\title{
Virus Heartland: un Bunyaviridae trasmitido por garrapatas en América
}

\author{
Heartland virus: a tick-borne Bunyaviridae in America \\ Iván Renato Zúñiga Carrasco,* Janett Caro Lozano \\ * Jefe del Departamento de Epidemiología. Unidad de Medicina Familiar 223 IMSS Lerma, México. \\ ‡ Jefa del Departamento de Epidemiología. Hospital General de Zona. Clínica de Medicina Familiar 1. IMSS Chetumal, Quintana Roo. México.
}

RESUMEN

\begin{abstract}
El virus Heartland es un Bunyaviridae Phlebovirus, agente causal de una enfermedad humana caracterizada por trombocitopenia y leucopenia. Las garrapatas Amblyomma americanum y Dermacentor variabilis han sido implicadas como vectores. La alta seroprevalencia asociada con abundancia local de venados cola blanca y mapaches demostró que estas especies pueden ser huéspedes amplificadores. La mayoría de los pacientes presentan fiebre $\left(\geq 38.0^{\circ} \mathrm{C}\right)$, trombocitopenia, leucopenia, fatiga, anorexia, dolor de cabeza, náuseas, mialgia y artralgia.
\end{abstract}

Palabras clave: Virus Heartland, Bunyaviridae, garrapata.

\section{INTRODUCCIÓN}

El virus Heartland (VHRT), de la familia Bunyaviridae, género Phlebovirus, es una enfermedad que se informó por primera vez en dos agricultores en el noroeste de Missouri en 2009. Siete casos más se notificaron (dos de ellos mortales) en Missouri, Tennessee y Oklahoma. Un estudio de garrapatas y mosquitos en el noroeste de Missouri detectó VHRT en Amblyomma americanum, lo que relacionó a este insecto como vector. El virus fue aislado de ninfas que presumiblemente fueron infectadas cuando eran larvas, después de alimentarse de un vertebrado anfitrión. EI VHRT aún no se ha aislado del entorno salvaje o animales domésticos, la cuestión de los depósitos de vertebrados permanece sin respuesta. Sin embargo, la alta prevalencia en venados cola blanca (Odocoileus virginianus) seropositivos y

\section{ABSTRACT}

The Heartland Virus is a Bunyaviridae, Phlebovirus causative agent, of a human disease characterized by thrombocytopenia and leukopenia. Amblyomma americanum and Dermacentor variabilis ticks have been implicated as vectors. The high seroprevalence associated with local abundances of white-tailed deer and raccoons demonstrated that these species can be amplifying hosts. Most patients present with fever $\left(\geq 38.0^{\circ} \mathrm{C}\right)$, thrombocytopenia, leukopenia, fatigue, anorexia, headache, nausea, myalgia, and arthralgia.

Keywords: Heartland Virus, Bunyaviridae, tick.

mapaches (Procyon lotor) son indicativos para la vigilancia serológica de la vida silvestre. ${ }^{1}$

\section{EPIDEMIOLOGÍA}

EI VHRT puede transmitirse por la picadura de la garrapata (Amblyomma americanum). No se sabe si otras especies de garrapatas pueden transmitirlo. ${ }^{2}$

Genéticamente, el VHRT está más relacionado con el virus del síndrome de la fiebre grave con trombocitopenia (VSFGT). EI VHRT se ha asociado con un gran número casos en China y Corea del Sur, lo que indica su presencia continua en el transcurso del año, con una amplia extensión geográfica. El VHRT circula en un ciclo enzoótico y se extiende a los humanos cuando están expuestos a garrapatas infectadas. ${ }^{3}$

Entre los huéspedes de VHRT se encuentran animales domésticos y salvajes, de estos últimos, el

Citar como: Zúñiga CIR, Caro LJ. Virus Heartland: un Bunyaviridae trasmitido por garrapatas en América. Rev Latin Infect Pediatr. 2021; 34 (3): 118-119. https://dx.doi.org/10.35366/102233

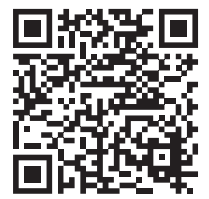


venado cola blanca muestra la tasa más alta (64\%), seguido de mapaches (55-68\%), caballos (22\%) y perros $(8 \%)^{4,5}$

\section{CLÍNICA}

Los signos y síntomas de la enfermedad del VHRT son similares a los de la ehrlichiosis o la anaplasmosis. La mayoría de los pacientes han reportado mordedura de garrapata dos semanas antes de los síntomas. Además, la mayoría han informado fiebre, fatiga, anorexia, cefalea, náuseas, diarrea, así como mialgias y artralgias. Algunos pacientes presentan una erupción local que a menudo se asocia con la picadura primigenia. ${ }^{2,4}$

Hallazgos patológicos: presencia de esplenomegalia y eritrofagocitosis con hiperplasia histiocítica en médula ósea, bazo y ganglios linfáticos, y linfohistiocitosis hemofagocítica (LHH). Los hallazgos del sistema nervioso central (SNC) incluyen múltiples infartos cerebrales sin evidencia de meningitis 0 encefalitis. ${ }^{6}$

Laboratorio: los datos de estudios de laboratorio muestran anemia normocítica y trombocitopenia. EI recuento total de leucocitos llega a estar dentro del rango de referencia, pero el recuento de linfocitos puede mostrar linfopenia absoluta. La troponina I está ligeramente elevada sin cambios electrocardiográficos.

Los resultados de punción lumbar revelan proteínas en el líquido cefalorraquídeo (LCR) levemente elevadas y un nivel de glucosa en el LCR de $\geq 65 \mathrm{mg} / \mathrm{dL}$.

Todos los individuos con enfermedad aguda por VHRT Ilegan a tener trombocitopenia, leucopenia, leucocitosis, anemia, niveles elevados de enzimas, aspartato aminotransferasa (AST) y alanina aminotransferasa (ALT), que normalmente alcanza su punto máximo en la segunda semana de la enfermedad, y los niveles de AST son, al menos, 2-3 veces más altos que niveles ALT. Otras anomalías de laboratorio observadas, particularmente en pacientes con enfermedades más graves, incluyen: hiponatremia, bilirrubina elevada, aumento de creatincinasa, lactato y ferritina notablemente aumentados. Los casos presentan aumento de ferritina, linfohistiocitosis hemofagocítica $(\mathrm{LHH})$; hemofagocitosis en su médula ósea con inmunotinción granular de antígenos virales en las células mononucleares. Para los casos fatales, todos progresan a lesión y falla renal, falla respiratoria e hipotensión, sepsis, falla orgánica multisistémica, choque y muerte. ${ }^{4,6,7}$

\section{DIAGNÓSTICO}

Las pruebas actuales disponibles para la infección por el VHRT incluyen reacción reversa en cadena de polimerasa con transcriptasa inversa (RTPCR, por sus siglas en inglés), así como neutralización por reducción en placas para medir anticuerpos neutralizantes específicos. ${ }^{7}$

\section{TRATAMIENTO}

No hay terapias antivirales conocidas disponibles para tratar la infección por VHRT, el manejo de la enfermedad aguda es principalmente de tipo conservador. Se pueden usar antipiréticos y analgésicos para reducir la fiebre y dolor. Los casos más graves pueden necesitar soporte de ventilación, vasopresores, suplementos sanguíneos o diálisis. ${ }^{4,7}$

Se pueden administrar antibióticos ante la sospecha de ehrlichiosis ya que, como se comentó previamente, la presentación clínica es similar, si no hay mejoría clínica dentro de 48 a 72 horas de la prescripción de tetraciclinas, se demuestra que la condición etiológica es diferente. ${ }^{7}$

\section{REFERENCIAS}

1. Riemersma K, Komar N. Heartland virus neutralizing antibodies in vertebrate wildlife, United States 2009-2014. Emerg Infect Diseas. 2015; 21 (10): 1830-1833.

2. Indiana State. Department of Health. Epidemiology Resource Center. Heartland Virus Quick Facts. 2018.

3. Bosco A, Calvert A, Root J, Gidlewski T, Bird B. Vertebrate host susceptibility to Heartland virus. Emerg Infect Diseas. 2016; 22 (12): 2070-2077.

4. Brault A, Savage H, Duggal N, Eisen R, Staples E. Heartland virus epidemiology, vector association and disease potential. Viruses. 2018; 10 (9): 498.

5. Savage H, Godsey M, Lambert A, Panella N, Burkhalter K. First detection of Heartland virus (Bunyaviridae: Phlebovirus) from field collected arthropods. Am J Trop Med Hyg 2013; 89 (3): 445-452.

6. Carlson A, Pastula D, Lambert A, Staples E, Muehlenbachs A. Heartland virus and hemophagocytic lymphohistiocytosis in immunocompromised patient, Missouri, USA. Emerg Infect Diseas. 2018; 24 (5): 893-897.

7. Mestrovic T. Heartland Virus Clinical Presentation. Available in: https://www.news-medical.net/health/Heartland-VirusClinical-Presentation.aspx

Financiamiento: Ninguno.

Conflicto de intereses: Ninguno.

Correspondencia:

Iván Renato Zúñiga Carrasco

E-mail: ivan.zuñiga@imss.gob.mx 